\title{
Risk assessment of sepsis through measurement of proAVP (copeptin): a secondary analysis of the TRIAGE study
}

\author{
Milena Kloter ${ }^{1,2}$, Claudia Gregoriano ${ }^{1}$, Ellen Haag ${ }^{1,2}$, Alexander Kutz ${ }^{1,2}$, Beat Mueller ${ }^{1,2}$ and Philipp Schuetz ${ }^{1,2}$ \\ ${ }^{1}$ Medical University Department of Medicine, Kantonsspital Aarau, Aarau, Switzerland \\ ${ }^{2}$ Faculty of Medicine, University of Basel, Basel, Switzerland
}

Correspondence should be addressed to M Kloter: milena.kloter@hotmail.com

\begin{abstract}
Objective: Systemic infections and sepsis lead to strong activation of the vasopressin system, which is pivotal for stimulation of the endocrine stress response and, in addition, has vasoconstrictive and immunomodulatory effects. Our aim was to assess the significance of the vasopressor system through measurement of C-terminal proAVP (copeptin) regarding mortality prediction in a large prospective cohort of patients with systemic infection.

Design and methods: This secondary analysis of the observational cohort TRIAGE study included consecutive, adult, medical patients with an initial diagnosis of infection seeking emergency department care. We used multivariable regression analysis to assess associations of copeptin levels in addition to the Sequential Organ Failure Assessment (SOFA) score with 30-day mortality. Discrimination was assessed by calculation of the area under the curve (AUC).

Results: Overall, 45 of 609 (7.4\%) patients with infection died within 30 days. Non-survivors had a marked upregulation of the vasopressin system with a more than four-fold increase in admission copeptin levels compared to non-survivors (199.9 \pm 204.7 vs 46.6 $\pm 77.2 \mathrm{pmol} / \mathrm{L}$ ). In a statistical model, copeptin was significantly associated with mortality (adjusted odds ratio of $1.04,95 \% \mathrm{Cl} 1.01$ to $1.07, P=0.002$ ). Regarding discrimination, copeptin alone showed an AUC of 0.82 , while adding copeptin to the SOFA score significantly improved its prognostic ability (AUC 0.83 vs $0.86, P=0.027$ ).

Conclusion: Activation of the vasopressin system mirrored by an increase in copeptin levels provided significant information regarding mortality risk and improved the SOFA score for prediction of sepsis mortality.
\end{abstract}

\section{Introduction}

Systemic infection leading to sepsis contributes to a major portion of patients seeking care in the emergency department (ED) and the intensive care unit (ICU) $(1,2)$. Sepsis has been defined as life-threatening organ dysfunction caused by a dysregulated host response to infection and is associated with increased use of healthcare resources and mortality $(3,4)$. Sepsis leads to strong physiological activation of the vasopressin system aiming to co-stimulate the endocrine stress response and stabilize blood hemostasis through vasoconstrictive effects and the overwhelming immune response through immunomodulatory effects (5). While pharmacological treatment of sepsis patients with vasopressin did not appear to lower mortality (6), measuring the activation https://ec.bioscientifica.com

https://doi.org/10.1530/EC-21-0211 (c) 2021 The authors Published by Bioscientifica Ltd

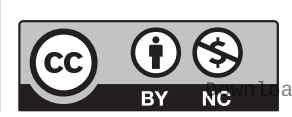

This work is licensed under a Creative Commons Attribution-NonCommercial 4.0 International License. ded from Bioscientifica.com at 04/26/2023 01:01:55PM 
of the vasopressin system could provide important prognostic information regarding the severity of the infection and associated mortality risks.

Estimating severity and risk for mortality has become the main focus in the initial assessment of sepsis. It has become clear that organ dysfunction is both a hallmark of severe systemic infection and a main prognostic indicator $(7,8)$. According to current guidelines, the diagnosis of sepsis thus also relies on the sequential organ failure assessment (SOFA), which reflects the individual degree of organ dysfunction (9). However, relying on SOFA still is not perfect, and there is misclassification of patients regarding their true mortality risk. Thus, improving SOFA by the addition of other prognostic indicators is important. Herein, novel biomarkers mirroring fluid and endocrine activation may be helpful $(1,10,11,12)$. Hemodynamic instability, including vascular tone loss, decreased arterial blood pressure and tissue perfusion, occurs in sepsis and in septic shock resulting in activation of counteracting mediators $(13,14)$. This includes activation of the arginine vasopressin (AVP) on the hypothalamic-pituitary-adrenal (HPA) axis $(15,16,17)$. As AVP is hard to measure due to the instability and short half-life, the more stable pre-hormone copeptin (39-amino acid C-terminal portion of proAVP) may be measured instead $(14,18,19,20)$. Copeptin has previously been shown to provide prognostic information in patients with stroke and infection of the lung $(10,21,22$, $23,24)$, as well as for critically ill patients with sepsis (13, $25,26,27,28)$. However, to our knowledge, there is a lack of studies investigating whether the addition of copeptin to SOFA could improve the prognostic assessment of patients by providing information regarding activation of the vasopressin system.

Our aim was to assess the significance of the activation of the vasopressor system through measurement of copeptin in addition to SOFA regarding mortality prediction in a large prospective cohort of patients with systemic infection.

\section{Materials and methods}

\section{Study design, setting and patient sample}

This is a secondary analysis of the prospective TRIAGE study (1), a multi-national, observational cohort study, which recruited consecutive ED patients with any symptoms in Aarau (Switzerland), Paris (France), and Clearwater (FL, USA) between March 2013 and October 2014. The study protocol (29) and main results (1) have been published previously. The Institutional Review Board of all centers approved the protocol and waived the need for individual information content due to the observational design of the study (main Swiss IRB: Ethic Commission of the Canton Aargau: registration number: EK-2012/059). The TRIAGE study was registered at the "ClinicalTrials. gov" website (http://www.clinicaltrials.gov/ct2/show/ NCT01768494, last access 19.02.2021).

For this secondary analysis, only medical patients presenting at the tertiary care hospital in Aarau (Switzerland) with a main diagnosis of infection were included. Thus, all patients had a main infection diagnosis, which was verified through their Swiss diagnosis-related groups (DRG) coding at discharge (from: https://www. swissdrg.org, last access 19.02.2021). Surgical and pediatric patients were not part of the study.

\section{Data collection and selection}

All included participants provided a medical history and underwent a physical examination, including measurement of vital signs, laboratory assessment and collection of leftover blood samples. We also recorded socio-demographical data, clinical symptoms, complaints, and comorbidities. Patient' outcomes, including admission toICU and length of hospital stay (LOS), were collected by chart review, if necessary. Missing data was supplemented through chart abstraction and automatic export from the internal medical data system. All included patients were contacted 30 days after hospital admission via telephone interview to assess their vital status.

\section{Primary and secondary endpoints}

Consistent with the initial study, the primary endpoint of this analysis was defined as all-cause 30-day mortality. Secondary endpoints were defined as admission to the ICU within 30 days following ED admission and positive blood cultures during the hospital stay.

\section{Definitions of infection at ED admission}

For this analysis, we grouped patients into pre-specified groups based on the main focus of infection, namely respiratory tract infection (including communityacquired pneumonia, chronic obstructive pulmonary disease (COPD)-exacerbation, asthma-exacerbation, bronchitis), urinary tract infection, skin infection, gastrointestinal infection, CNS infection, and other types of infections.

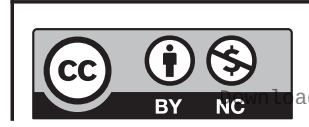

This work is licensed under a Creative Commons Attribution-NonCommercial 4.0 International License. ded from Bioscientifica.com at 04/26/2023 01:01:55PM 


\section{SOFA score calculation}

In order to identify organ dysfunction caused by a dysregulated host response to infection, the SOFA score as proposed by the 'Third International Consensus Definitions for Sepsis and Septic Shock' was used (30). The score evaluates different organ systems (respiratory, coagulation, liver, cardiovascular, central nervous, and renal), which require laboratory and clinical variables for assessment and computation (9). Because the main entry point of the study was the ED and not all patients had an arterial blood gas analysis taken, we used an adapted score as previously proposed relying on the $\mathrm{SO}_{2} / \mathrm{FiO}_{2}$ index instead of the $\mathrm{pO}_{2} / \mathrm{FiO}_{2}$ index (9). If the route of $\mathrm{O}_{2}$ administration was unknown, we assumed a $\mathrm{FiO}_{2}$ of 0.3 for patients with nasal $\mathrm{O}_{2}$ administration according to the previous study (31). For the cardiovascular system, 0 points were assigned for mean arterial pressure (MAP) $\geq 70 \mathrm{mmHg}$ and 1 point for $\mathrm{MAP}<70 \mathrm{mmHg}$ as specified in the original SOFA score calculation.

\section{Copeptin measurement and other markers of the osmotic system}

For the analysis of these copeptin values, there were no new measurements performed. The analyzed copeptin data were measured during the TRIAGE study and are original data from there. For this, leftover samples of routinely collected blood samples upon admission were immediately centrifuged, aliquoted and frozen at $-20^{\circ} \mathrm{C}$ for later batch analysis of copeptin. Copeptin was batchmeasured in plasma with a new sandwich immunoassay as described elsewhere $(14,32)$. The assays have analytical detection limits of $0.4 \mathrm{pmol} / \mathrm{L}$. We also recorded other markers influencing the osmotic system, such as sodium, osmolality and glomerular filtration rate (GFR) from the routine laboratory assessment.

\section{Statistical analysis}

All statistical analyses were performed using STATA 15.1 (StataCorp LLC). For descriptive statistics, discrete variables are expressed as frequency (percentage) and continuous variables are expressed as mean with S.D. or as medians with interquartile range (IQR). Imputation methods were used to complete data missing less than $10 \%$ of values. Univariable and multivariable logistic regression models with primary and secondary endpoints were used to examine the association of copeptin and other markers. Laboratory values with non-normal distribution were normalized through log-transformation before being entered into the statistical models. Odds ratios (OR), including the corresponding 95\% CIs were reported as a measure of association. We predefined three types of regression models, namely an unadjusted model (model 1), a model adjusted for age, sex, type of infection and comorbidities (model 2), and a model adjusted for age, sex, type of infection, comorbidities and SOFA score (model 3). The area under the receiver-operator-curve (ROC-AUC) was calculated as a measure of discrimination. Moreover, we also investigated subgroups for differences in performance based on socio-demographic factors (age and sex), type of infection and fluid balance makers.

\section{Results}

\section{Patient population}

This analysis includes a total of 654 medical inpatients presenting with a main diagnosis of infection to the ED of the Cantonal Hospital Aarau (Switzerland). The median age was $61 \pm 20$ years and $56 \%(n=365)$ of the patients were male. The mean SOFA score was 1.5 points $( \pm 2)$ and $62.4 \%$ of patients had a SOFA score $<2$ points. Regarding focus of infection, respiratory tract infection $(n=272,41.6 \%)$ and urinary tract infection ( $n=154,23.5 \%)$ were most frequent. Almost $30 \%$ of patients had chronic kidney disease ( $n=184)$. Overall, a total of 45 patients $(6.9 \%)$ reached the primary endpoint of all-cause 30-day mortality. Baseline characteristics of the patient population overall and stratified according to the primary endpoint are presented in Table 1.

\section{Association of SOFA, copeptin and fluid balance markers with primary and secondary endpoints}

Overall, initial SOFA score values were three-fold higher in patients who died compared to survivors $(4.2 \pm 2.7$ vs $1.3 \pm 1.8, P<0.001$ ) (Table 2 ). Also, copeptin levels upon admission were four-fold higher in non-survivors compared to survivors $(199.9 \pm 204.7 \mathrm{pmol} / \mathrm{L}$ vs $46.6 \pm 77.2$ pmol/L). In an unadjusted logistic regression analysis (model 1), we found an association of copeptin with an OR of 1.08 (95\% CI 1.06, 1.10, $P<0.001)$ for the primary endpoint 30-day mortality. These results remained robust in the multivariable model 2 (OR 1.06 (95\% CI 1.04, 1.09), $P<0.001$ ), adjusted for age, sex, type of infection and comorbidities, as well as in the multivariable model 3 adjusted for age, sex, type of infection, comorbidities

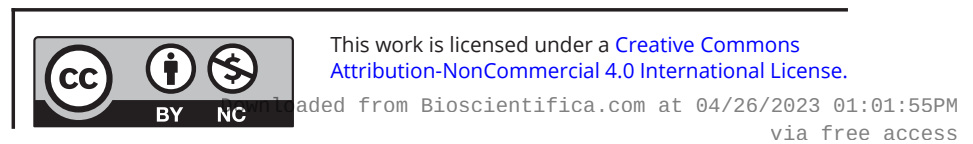


Table 1 Baseline characteristics of the overall cohort and stratified by primary endpoint.

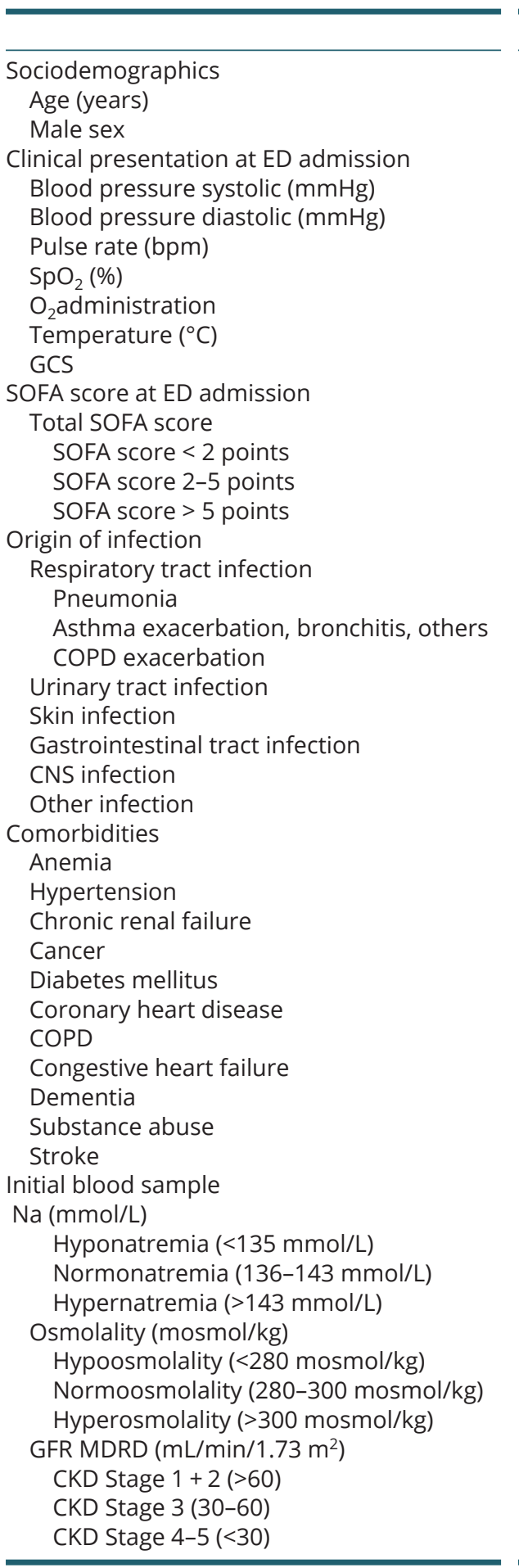

\begin{tabular}{c}
\hline All $(n=654)$ \\
\hline \\
$61.0(20.3)$ \\
$365(55.8 \%)$ \\
$129.9(22.6)$ \\
$74.8(15.3)$ \\
$90.4(19.5)$ \\
$93.8(4.5)$ \\
$119(18.3 \%)$ \\
$37.9(1.1)$ \\
$14.7(1.2)$ \\
$1.5(2.0)$ \\
$408(62.4 \%)$ \\
$208(31.8 \%)$ \\
$38(5.8 \%)$ \\
$272(41.6 \%)$ \\
$135(49.6 \%)$ \\
$120(44.1 \%)$ \\
$17(6.3 \%)$ \\
$154(23.5 \%)$ \\
$59(9.0 \%)$ \\
$39(6.0 \%)$ \\
$17(2.6 \%)$ \\
$113(17.3 \%)$ \\
$32.2(14.9)$ \\
$410(62.7 \%)$ \\
$175(26.8 \%)$ \\
$69(10.6 \%)$ \\
$305(48.3 \%)$ \\
$184(28.1 \%)$ \\
$122(18.7 \%)$ \\
$119(18.2 \%)$ \\
$89(13.6 \%)$ \\
$53(8.1 \%)$ \\
$47(7.2 \%)$ \\
$45(6.9 \%)$ \\
$27(4.1 \%)$ \\
$26(4.0 \%)$ \\
$136.8(4.3)$ \\
$214(32.7 \%)$ \\
$414(63.3 \%)$ \\
\\
$26)$ \\
\\
\end{tabular}

\begin{tabular}{c}
\hline Survivors $(n=609)$ \\
\hline \\
$59.8(20.3)$ \\
$336(55.2 \%)$ \\
$130.7(22.0)$ \\
$75.5(14.3)$ \\
$89.8(19.0)$ \\
$94.0(4.3)$ \\
$95(15.7 \%)$ \\
$37.9(1.1)$
\end{tabular}

\begin{tabular}{c}
\hline Non-survivors $(n=45)$ \\
$78.3(10.2)$ \\
$29(64.4 \%)$
\end{tabular}

$14.8(0.8)$

$119.3(27.2)$

0.23

$1.3(1.8)$

$401(65.8 \%)$

$187(30.7 \%)$

$21(3.5 \%)$

0.001

$64.6(23.1) \quad<0.001$

$97.7(24.4) \quad 0.010$

$91.2(5.6)<0.001$

$24(54.5 \%) \quad<0.001$

$37.7(1.0) \quad 0.26$

$13.4(3.1) \quad<0.001$

$246(40.4 \%)$

$117(47.6 \%)$

$115(46.7 \%)$

$14(5.7 \%)$

$145(23.8 \%)$

$56(9.2 \%)$

$35(5.7 \%)$

$17(2.8 \%)$

$110(18.1 \%)$

$4.2(2.7)$

$<0.001$

$7(15.5 \%)$

$21(46.6 \%)$

$17(37.9 \%)$

$26(57.8 \%)$

$18(69.2 \%)$

$5(19.2 \%)$

$3(11.5 \%)$

$9(20.0 \%)$

$3(6.7 \%)$

$4(8.9 \%)$

$0(0.0 \%)$

$3(6.7 \%)$

$279(42.7 \%)$

$278(45.6 \%)$

$155(25.5 \%)$

$106(17.4 \%)$

$108(17.7 \%)$

$73(12.0 \%)$

$42(6.9 \%)$

$42(6.9 \%)$

$37(6.1 \%)$

$26(4.3 \%)$

$24(3.9 \%)$

37 (5.7\%)

$<0.001$

27 (60.0\%)

29 (64.4\%)

0.063

16 (35.6\%)

$<0.001$

$11(24.4 \%)$

0.003

16 (35.6\%)

0.26

$11(24.4 \%)$

$<0.001$

$5(11.1 \%)$

$<0.001$

$8(17.8 \%)$

0.29

1 (2.2\%)

0.003

$2(4.4 \%)$

0.51

$136.7(4.2)$

$199(32.7 \%)$

$390(64.0 \%)$

$20(3.3 \%)$

$288.4(10.6)$

$99(16.3 \%)$

$458(75.2 \%)$

$52(8.5 \%)$

$53.4(13.9)$

399 (65.5\%)

$158(25.9 \%)$

$137.4(6.1)$

0.34

15 (33.3\%)

$24(53.3 \%)$

$6(13.3 \%)$

$297.6(14.9)$

2 (4.4\%)

$<0.001$

25 (55.6\%)

$18(40.0 \%)$

$37.2(18.7)$

$11(24.4 \%)$

$17(37.8 \%)$

$52(8.5 \%)$

$17(37.8 \%)$

COPD, chronic obstructive pulmonary disease; ED, emergency department; GCS, Glasgow Coma Scale; GFR, glomerular filtration rate; MDRD, modification of diet in renal disease; SOFA score, sequential organ failure assessment score; $\mathrm{SpO}_{2}$, peripheral capillary oxygen saturation.

and SOFA score (OR 1.04 (95\% CI 1.01, 1.07), $P=0.002$ ). Copeptin also showed an association for the two secondary endpoints - ICU admission and blood culture positivity in the unadjusted model (model 1). However, in the two adjusted models (model 2 and model 3), the association was no longer significant for both secondary endpoints.

Regarding discrimination, copeptin was the strongest for 30-day mortality, with an AUC of 0.82 compared to

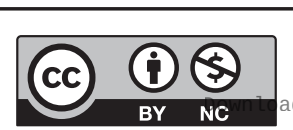



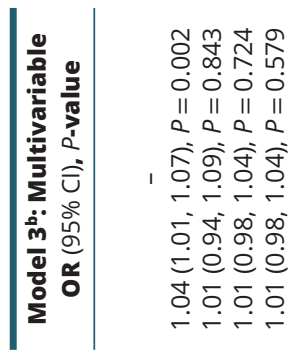

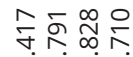

$\circ 000$

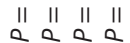

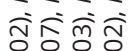

다

ถ้ก๊ำ

이이

ํํ용

ஸ̆ ஜ

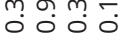

II 11 II

a.s.

ชे

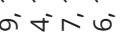

คิ คำ

ธ. 유 ศ़

둥이

бㅎํํํํㅎํ

०.0.0

a cana

बึ.

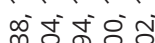

=ं巳்

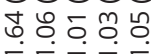

훙요요

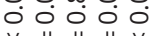

$0<0<a$

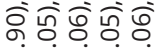

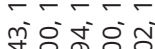

ᄃㄷㄷ

กูก

ธํํㅇํํํํ

००००ं

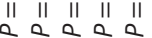

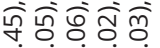

- $-\div$

ஜ் ถัฒ

$\leftarrow=000$

กิํㅇㅇㅇํ

Cr.

N

бㅎํㅎํㅇㅎㅁ

o. 000

a cana

흥ํํㅎํㅇㅎํ

ธㅎํ유유

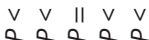

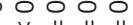

$\begin{array}{llll}0 & 0 & 0 & 0 \\ 0 & 0 & 0\end{array}$

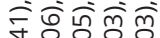

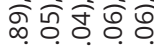

$\dot{\sim}+\dot{r}+\dot{r}$

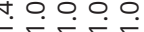

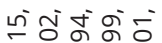

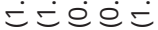

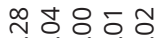

$-$

$=こ ?=$

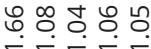

$\infty$ ఫ̊

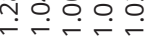

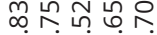

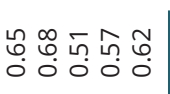

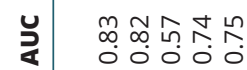

00000

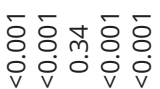

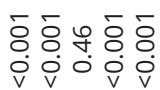

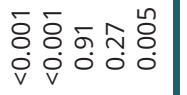

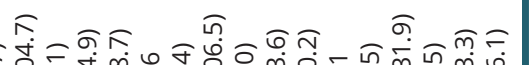

भก 岂导

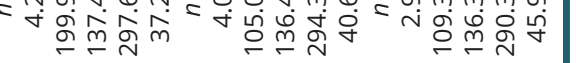

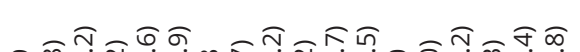

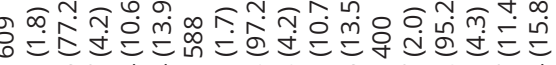

$\|m \omega \wedge \forall \forall\| m \infty \infty$ n $6 \| N N m N$

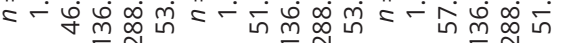

年
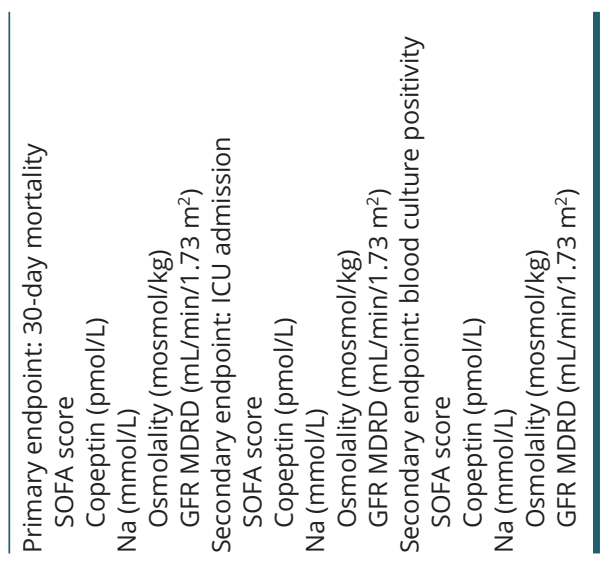

the other fluid balance markers including Na (AUC 0.57), osmolality (AUC 0.74) and GFR (AUC 0.75) and similar to the SOFA score (AUC 0.82). We also compared AUCs of copeptin among different predefined patient subgroups. As demonstrated in Fig. 1, results were similar in the subgroup stratified by gender, type of infection, $\mathrm{Na}$ concentration and osmolality. However, a significant effect modification was found for urinary tract infection and CKD stage 3 ( $P$ for interaction $<0.05$ ). We also investigated the same subgroups regarding SOFA score, where a subgroup effect was found for patients aged under 60 years (AUC 0.94) and for patients with CKD stages 4 and 5 (AUC of 0.53 (Fig. 2).

In the next step, we investigated whether the combination of SOFA score with copeptin and other fluid balance markers would further improve its prognostic potential. Table 3 shows the AUC of different bivariable and multivariable models combining different parameters. Adding copeptin to SOFA significantly improved its AUC from 0.83 to $0.86(P=0.028)$. Further addition of markers did only slightly provide better prognostication as assessed by improvements in AUC and none of the other markers improved the SOFA score, except MR-proADM which showed the same improvement as copeptin (AUC from 0.83 to $0.86, P=0.002)$. Also, regarding blood culture positivity, copeptin improved the SOFA score from AUC 0.65 to 0.68 , while none of the other markers had a similar effect. Finally, regarding admission to ICU, osmolality but not copeptin improved the model.

\section{Association of copeptin ICU admission and blood culture positivity}

The SOFA score alone showed the best discrimination for the secondary endpoint of ICU admission as well (AUC 0.83) followed by copeptin with an AUC of 0.75. In contrast, regarding blood culture positivity, copeptin performed the best (AUC 0.68) followed by SOFA score (AUC 0.65), which nevertheless remained very weak. Results of the regression analysis and discrimination values are shown in Table 2 .

Figure 3 illustrates the SOFA score together with copeptin, whereby stratification by age found higher AUC for 60 to 80 years (AUC 0.98) and a $P$ for interaction of $<0.05$ for stage 1 and 2 CKD.

\section{Discussion}

The key findings of this analysis are two-fold. First, we found that the activation of the vasopressin

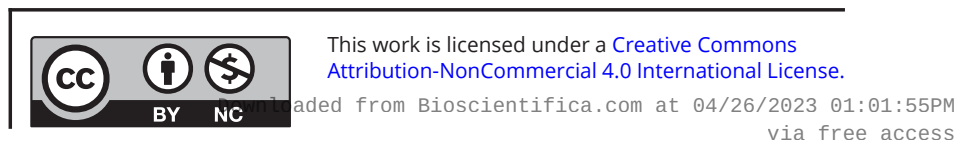



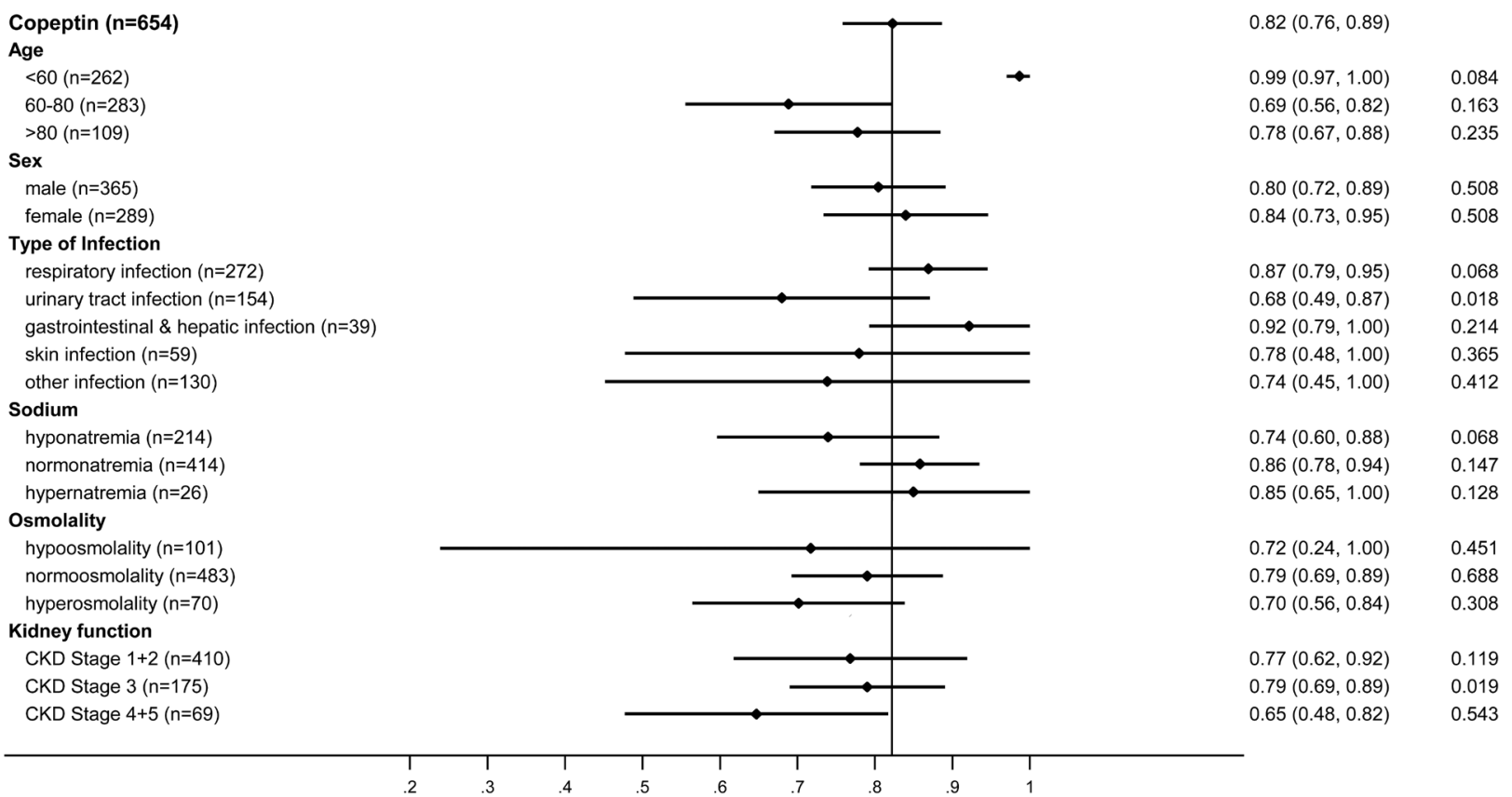

Figure 1

Prognostic performance of copeptin as predictor for 30-day mortality stratified by age, sex, type of infection, and fluid balance markers (sodium, osmolality and kidney function) to evaluate subgroup differences. The vertical reference line mirrors the overall AUC. AUCs to the right of the reference line indicate higher levels of discrimination, AUCs to the left of the reference line indicate lower levels of discrimination. The forest plot shows different levels of discrimination with their respective $95 \%$ Cls by subgroups. $P$ for interaction indicates the level of effect modification by subgroups.

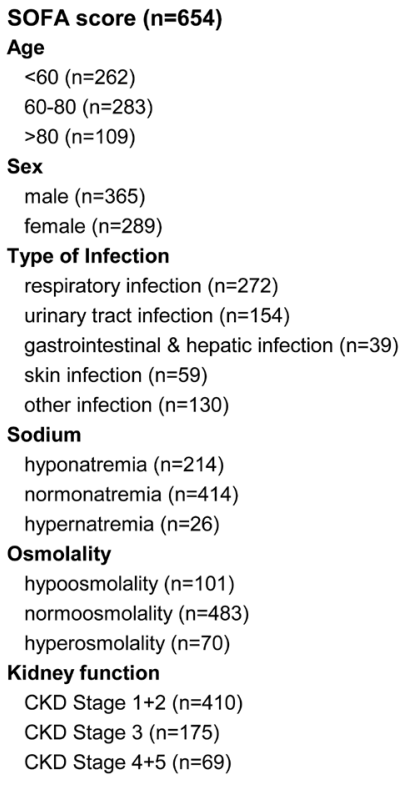

ROC-AUC (95\% Cl) P-Interaction $0.82(0.77,0.88)$

$0.94(0.87,1.00) \quad 0.828$ $0.75(0.65,0.86) \quad 0.305$ $0.78(0.67,0.89) \quad 0.27$ $0.83(0.76,0.89) \quad 0.898$ $0.81(0.70,0.92) \quad 0.898$ $0.86(0.80,0.93) \quad 0.088$ $0.72(0.55,0.90) \quad 0.575$ $0.89(0.75,1.00) \quad 0.748$ $0.76(0.61,0.91) \quad 0.05$ $0.73(0.28,1.00) \quad 0.998$

$0.76(0.64,0.88) \quad 0.074$ $0.84(0.76,0.91) \quad 0.467$ $0.93(0.83,1.00) \quad 0.241$

$0.94(0.87,1.00) \quad 0.426$ $0.79(0.70,0.87) \quad 0.228$ $0.72(0.57,0.87) \quad 0.953$

$0.82(0.66,0.97) \quad 0.01$ $0.74(0.61,0.87) \quad 0.296$ $0.53(0.35,0.71) \quad 0.007$

\section{Figure 2}

Prognostic performance of SOFA score as predictor for 30-day mortality stratified by age, sex, type of infection, and fluid balance markers (sodium, osmolality and kidney function) to evaluate subgroup differences. The vertical reference line mirrors the overall AUC. AUCs to the right of the reference line indicate higher levels of discrimination, AUCs to the left of the reference line indicate lower levels of discrimination. The forest plot shows different levels of discrimination with their respective $95 \%$ Cls by subgroups. $P$ for interaction indicates the level of effect modification by subgroups.

https://ec.bioscientifica.com https://doi.org/10.1530/EC-21-0211 (c) 2021 The authors Published by Bioscientifica Ltd

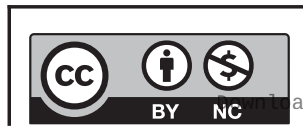

This work is licensed under a Creative Commons Attribution-NonCommercial 4.0 International License. ded from Bioscientifica.com at 04/26/2023 01:01:55PM 
Table 3 Association of various combinations of SOFA score with copeptin and fluid balance biomarkers for primary and secondary endpoints.

\begin{tabular}{|c|c|c|}
\hline & AUC $(95 \% \mathrm{Cl})$ & P-value \\
\hline \multicolumn{3}{|l|}{ Primary endpoint 30-day mortality } \\
\hline SOFA score & $0.83(0.77,0.88)$ & \\
\hline \multicolumn{3}{|l|}{ Change in AUC in bivariate analysis } \\
\hline SOFA score and $\mathrm{Na}$ & $0.83(0.77,0.88)$ & 0.7448 \\
\hline SOFA score and GFR & $0.84(0.78,0.89)$ & 0.0321 \\
\hline SOFA score and osmolality & $0.84(0.79,0.89)$ & 0.0861 \\
\hline SOFA score and copeptin & $0.86(0.81,0.91)$ & 0.0277 \\
\hline SOFA score and MR-proADM & $0.86(0.81,0.90)$ & 0.0016 \\
\hline \multicolumn{3}{|l|}{ Change in AUC in multivariate analysis } \\
\hline SOFA score and copeptin and osmolality and GFR & $0.87(0.82,0.92)$ & 0.0281 \\
\hline SOFA score and copeptin and osmolality and GFR and $\mathrm{Na}$ & $0.87(0.82,0.92)$ & 0.0289 \\
\hline SOFA score and copeptin and GFR & $0.87(0.82,0.92)$ & 0.0144 \\
\hline SOFA score and copeptin and MR-proADM & $0.87(0.83,0.92)$ & 0.0075 \\
\hline \multicolumn{3}{|l|}{ Secondary endpoint admission to ICU } \\
\hline SOFA score & $0.83(0.78,0.88)$ & \\
\hline \multicolumn{3}{|l|}{ Change in AUC in bivariate analysis } \\
\hline SOFA score and copeptin & $0.82(0.77,0.87)$ & 0.0546 \\
\hline SOFA score and $\mathrm{Na}$ & $0.82(0.77,0.87)$ & 0.3127 \\
\hline SOFA score and GFR & $0.82(0.78,0.87)$ & 0.4976 \\
\hline SOFA score and osmolality & $0.84(0.80,0.88)$ & 0.0155 \\
\hline \multicolumn{3}{|l|}{ Change in AUC in multivariate analysis } \\
\hline SOFA score and osmolality and GFR and $\mathrm{Na}$ and copeptin & $0.83(0.79,0.88)$ & 0.3516 \\
\hline SOFA score and osmolality and GFR and $\mathrm{Na}$ & $0.84(0.79,0.88)$ & 0.1387 \\
\hline SOFA score and osmolality and GFR & $0.84(0.79,0.88)$ & 0.0194 \\
\hline \multicolumn{3}{|l|}{ Secondary endpoint blood culture positivity } \\
\hline SOFA score & $0.65(0.59,0.72)$ & \\
\hline \multicolumn{3}{|l|}{ Change in AUC in bivariate analysis } \\
\hline SOFA score and GFR & $0.64(0.57,0.71)$ & 0.0589 \\
\hline SOFA score and osmolality & $0.65(0.58,0.71)$ & 0.7496 \\
\hline SOFA score and sodium & $0.65(0.58,0.72)$ & 0.9707 \\
\hline SOFA score and copeptin & $0.68(0.62,0.74)$ & 0.0144 \\
\hline \multicolumn{3}{|l|}{ Change in AUC in multivariate analysis } \\
\hline SOFA score and copeptin and $\mathrm{Na}$ and osmolality and GFR & $0.68(0.61,0.74)$ & 0.0900 \\
\hline SOFA score and copeptin and $\mathrm{Na}$ and osmolality & $0.68(0.61,0.74)$ & 0.0876 \\
\hline SOFA-score and copeptin and $\mathrm{Na}$ & $0.68(0.62,0.75)$ & 0.0104 \\
\hline
\end{tabular}

AUC, area under the curve; GFR, glomerular filtration rate; MR-proADM, mid-regional pro-adrenomedullin; SOFA score, sequential organ failure assessment score.

system mirrored by an increase in admission copeptin levels provided prognostic information regarding mortality. Secondly, when added to the SOFA score, this information further improved the early risk stratification of patients. The addition of fluid balance biomarkers, such as osmolality or $\mathrm{Na}$, did not provide such prognostic information.

Early and reliable risk stratification in patients presenting with signs and symptoms of infection and possible sepsis is important to reduce time to effective treatment and improve the site of care decisions $(1,2)$. For this purpose, SOFA is a well-established score with high prognostic accuracy regarding mortality (8). It has been shown that the vasoactive peptide mid-regional pro-adrenomedullin (MR-proADM) is able to improve the mortality risk stratification in patients with infection presenting to the ED beyond SOFA score alone and may further improve initial therapeutic site of care decisions (33). These findings were also shown for copeptin, as already mentioned above. Moreover, we have observed a further significant improvement of discrimination when adding both MR-proADM and copeptin to the SOFA score.

Physiopathologically, systemic infections lead to strong activation of the vasopressin system in order to balance vasodilatation by its vasoconstrictive and volumeretention effects. Often neglected vasopressin stimulates adreno-corticotropic hormone (ACTH) secretion in synergy with hypothalamic corticotroph-releasing hormone (CRH). Thus, vasopressin mediates and amplifies the hypothalamic-pituitary-adrenal stress response. Vasopressin also has immunomodulatory effects (5). Vasopressin also controls $\mathrm{Na}$ balance by free water retention

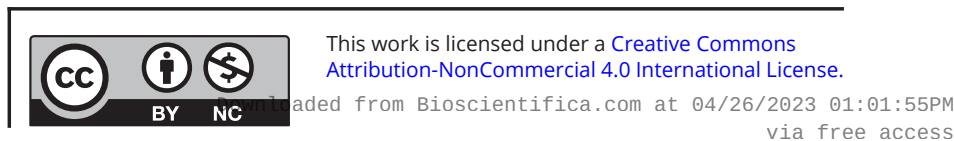



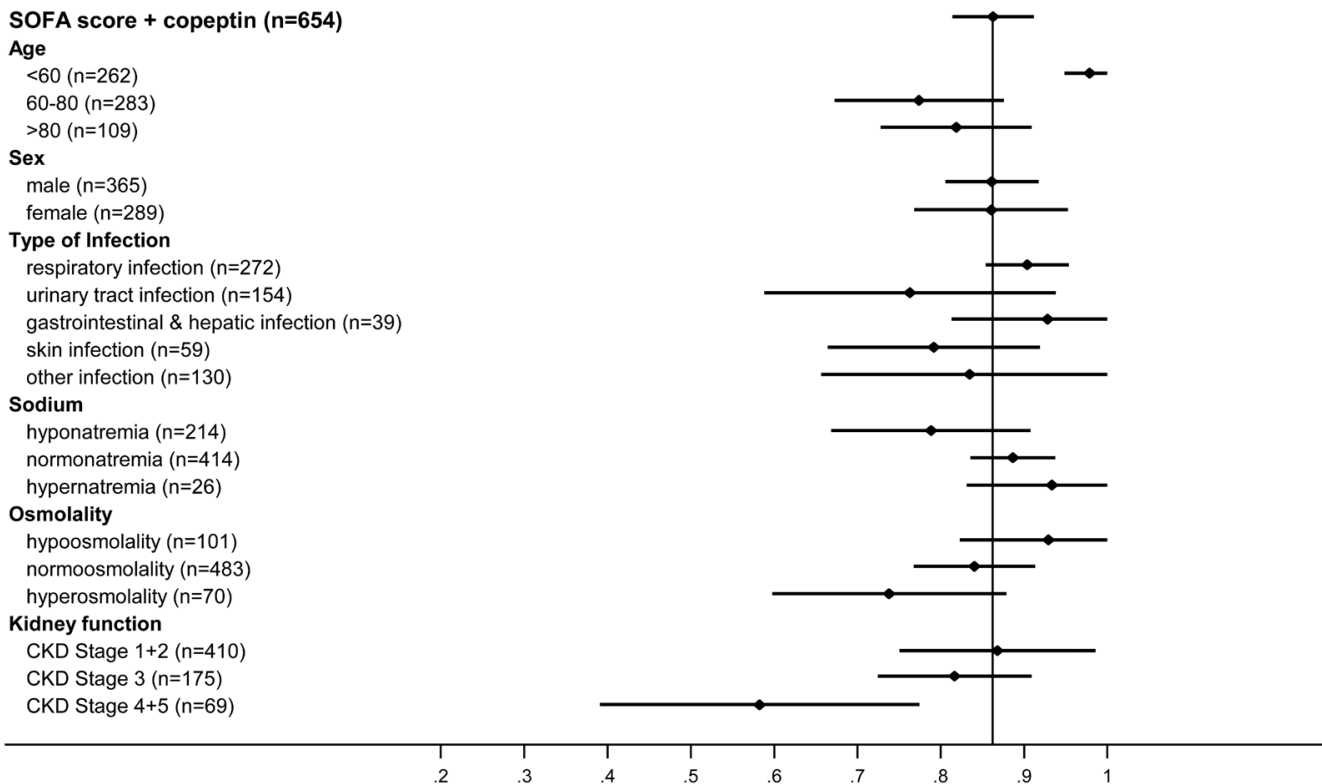

ROC-AUC $(95 \% \mathrm{Cl})$ P-Interaction $0.86(0.81,0.91)$

$\begin{array}{ll}0.98(0.95,1.00) & 0.118 \\ 0.77(0.67,0.88) & 0.096 \\ 0.82(0.73,0.91) & 0.607 \\ & \\ 0.86(0.81,0.92) & 0.425 \\ 0.86(0.77,0.95) & 0.425 \\ & \\ 0.90(0.85,0.95) & 0.053 \\ 0.76(0.59,0.94) & 0.113 \\ 0.93(0.81,1.00) & 0.756 \\ 0.79(0.66,0.92) & 0.309 \\ 0.83(0.66,1.00) & 0.507 \\ & \\ 0.79(0.67,0.91) & 0.244 \\ 0.89(0.84,0.94) & 0.641 \\ 0.93(0.83,1.00) & 0.227 \\ & \\ 0.93(0.82,1.00) & 0.584 \\ 0.84(0.77,0.91) & 0.395 \\ 0.74(0.60,0.88) & 0.183 \\ & \\ 0.87(0.75,0.99) & 0.002 \\ 0.82(0.72,0.91) & 0.062 \\ 0.58(0.39,0.77) & 0.04\end{array}$

Figure 3

Prognostic performance of SOFA score and copeptin as predictor for 30-day mortality stratified by age, sex-, type of infection, and fluid balance markers (sodium, osmolality and kidney function) to evaluate subgroup differences. The vertical reference line mirrors the overall AUC. AUCs to the right of the reference line indicate higher levels of discrimination, AUCs to the left of the reference line indicate lower levels of discrimination. The forest plot shows different levels of discrimination with their respective $95 \%$ Cls by subgroups. $P$ for interaction indicates the level of effect modification by subgroups.

in the kidney. In addition to the production of vasopressin in response to volume and osmolarity effects $(5,34)$, it is also a stress hormone that increases under physiological conditions of disease, including acute infections $(27,28)$. Physiological stress caused by infections or severe disease triggers the release of copeptin aiming to increase free water resorption in the kidney and thus maintaining blood pressure homeostasis through V2 receptors and inducing vasoconstriction of blood vessels through $\mathrm{V} 1$ receptors $(35,36,37)$. The physiological role of copeptin is not yet known. However, this peptide may have a role during intracellular processing of provasopressin, which contributes to the correct structural formation of the AVP precursor, which in turn leads to efficient proteolytic maturation (38). Despite unknown function, copeptin has been described as a surrogate of AVP for physiological conditions and in different diseases (39). Several studies found copeptin to be increased in different types of infections and to be associated with short-term mortality $(40,41)$. Our finding of higher copeptin levels in infections as a marker and mediator of the stress response is, thus, not surprising. To our knowledge, however, this is the first large-scale study investigating the additive effects of the vasopressor system through measurement of copeptin to the SOFA score, the current gold standard for sepsis diagnosis, regarding mortality risk.
Our results are in line with previous studies showing that fluid balance markers (i.e. sodium, osmolality, GFR) may improve risk prediction for infection in addition to organ dysfunction markers $(8,12)$. Interestingly, patients with respiratory, gastrointestinal or hepatic infections had the most benefit when applying SOFA score together with copeptin levels. Especially remarkable is the impact of kidney function on predicting 30-day mortality when the SOFA score is combined with copeptin. Mortality prediction remains significant regardless of the stage of chronic kidney disease, indicating dysregulated fluid homeostasis, which is also in line with other investigations (42). Taken together with other study results, this is evidence of the strong correlation of body fluid balance with infection and mortality (43).

It represents also a fluid balance marker, associated with urine osmolality and sodium, released by increased plasma osmolality, decreased arterial pressure and reductions in cardiac volume (44). Earlier investigations of copeptin focused primarily on vasopressin-dependent disorders of fluid homeostasis, such as hyponatremia, polydipsia and diabetes insipidus in the outpatient setting with a generally low stress level $(5,34)$ or acute cardiovascular illness $(45,46)$.

Based on the above-mentioned findings, one may hypothesize that risk stratification can be improved by

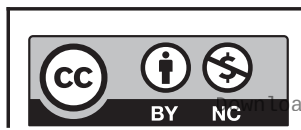

This work is licensed under a Creative Commons Attribution-NonCommercial 4.0 International License. ed from Bioscientifica.com at 04/26/2023 01:01:55PM 
assessing the SOFA score together with biomarkers, such as copeptin, in the initial assessment of patients with infection. One can expect better patient flow and a more adequate estimation of triage priority, which in turn may lead to lower ICU admissions and 30-day mortality rates. However, these findings must be investigated in further studies.

Our study has some limitations. First, because of the retrospective design of this analysis, we did not have all laboratory parameters and characteristics available, which would be of value in the context of copeptin measurement. We also used an adapted version of the SOFA score as not all patients had an arterial gas analysis done upon ED admission. Secondly, we limited all results to admission values only and no follow-up information regarding kinetics was available. Thirdly, we did not have a control patient population without infection to understand whether copeptin can discriminate between infectionrelated and non-infection-related deterioration in patients.

\section{Conclusion}

In conclusion, activation of the vasopressin system mirrored by an increase in copeptin levels provided significant information regarding mortality risk and improved the SOFA score for prediction of sepsis mortality.

\section{Declaration of interest}

P S and B M received research support paid to the Institution from Thermofisher, bioMerieux, Roche Diagnostics, Nestle Health Science and Abbott Nutrition. All other authors reported no conflicts of interest.

\section{Funding}

Thermofisher provided an unrestricted research grand for the initial TRIAGE study. P S was supported by the Swiss National Science Foundation (SNSF Professorship, PPO0P3 15031/1). This TRIAGE study was supported by the Swiss Academies of Arts and Sciences (SAMW).

\section{Author contribution statement}

M K, C G and E H managed the data collection. M K, C G and P S performed the statistical analyses and $M K$ and $C G$ drafted the manuscript. E H, A K, $\mathrm{B} \mathrm{M}$ and $\mathrm{P} \mathrm{S}$, amended and commented on the manuscript. All authors approved the final version.

\section{Acknowledgements}

This multidisciplinary and interprofessional trial was only possible in close collaboration of social services (Anja Keller, Regina Schmid), the nursing department (Susanne Schirlo, Petra Tobias), the central laboratory (Martha Kaeslin, Renate Hunziker), medical controlling (Juergen Froehlich, Thomas Holler, Christoph Reemts), IT (Roger Wohler, Kurt Amstad, Ralph Dahnke, Sabine Storost) of the Cantonal Hospital Aarau, Clinical Trial
Unit (CTU), University Hospital Basel (Thomas Fabbro, Guido Stirnimann, Patrick Simon), the department of Health Economics of the University of Basel (Stefan Felder, Timo Tondelli), as well as all participating patients, nurses and physicians. The TRIAGE study group includes members from the University Department of Internal Medicine, Cantonal Hospital Aarau, Switzerland (Ulrich Buergi, MD, Petra Tobias, RN, Eva Grolimund, MD, Ursula Schild, RN, Zeljka Caldara, RN, Katharina Regez, RN, Martha Kaeslin, Ursina Minder, RN, Renate Hunziker, RN, Andriy Zhydkov, MD, Timo Kahles, MD, Krassen Nedeltchev, MD, Petra Schäfer-Keller, PhD) the Clinical Trial Unit University Hospital Basel (Stefanie von Felten, PhD), the Institute of Nursing Science, University of Basel, Switzerland (Sabina De Geest, PhD); the Department of Psychology, University of Berne (Pasqualina PerrigChiello, PhD). The authors thank Erica Holt for native English review.

\section{References}

1 Schuetz P, Hausfater P, Amin D, Amin A, Haubitz S, Faessler L, Kutz A, Conca A, Reutlinger B, Canavaggio P, et al. Biomarkers from distinct biological pathways improve early risk stratification in medical emergency patients: the multinational, prospective, observational TRIAGE study. Critical Care 201519 377. (https://doi.org/10.1186/ s13054-015-1098-z)

2 Julian-Jimenez A, Candel-Gonzalez FJ \& Gonzalez Del Castillo J. Usefulness of inflammation and infection biomarkers in the Emergency Department. Enfermedades Infecciosas y Microbiologia Clinica 201432 177-190. (https://doi.org/10.1016/j.eimc.2013.01.005)

3 Prescott HC, Langa KM, Liu V, Escobar GJ \& Iwashyna TJ. Increased 1-year healthcare use in survivors of severe sepsis. American Journal of Respiratory and Critical Care Medicine 2014190 62-69. (https://doi. org/10.1164/rccm.201403-0471OC)

4 Prescott HC, Osterholzer JJ, Langa KM, Angus DC \& Iwashyna TJ. Late mortality after sepsis: propensity matched cohort study. BMJ 2016353 i2375. (https://doi.org/10.1136/bmj.i2375)

5 Christ-Crain M \& Fenske W. Copeptin in the diagnosis of vasopressindependent disorders of fluid homeostasis. Nature Reviews: Endocrinology 201612 168-176. (https://doi.org/10.1038/nrendo.2015.224)

6 Russell JA, Walley KR, Singer J, Gordon AC, Hebert PC, Cooper DJ, Holmes CL, Mehta S, Granton JT, Storms MM, et al. Vasopressin versus norepinephrine infusion in patients with septic shock. New England Journal of Medicine 2008358 877-887. (https://doi.org/10.1056/ NEJMoa067373)

7 Kadziolka I, Swistek R, Borowska K, Tyszecki P \& Serednicki W. Validation of Apache II and SAPS II scales at the intensive care unit along with assessment of SOFA scale at the admission as an isolated risk of death predictor. Anaesthesiology Intensive Therapy 201951 107-111. (https://doi.org/10.5114/ait.2019.86275)

8 Innocenti F, Bianchi S, Guerrini E, Vicidomini S, Conti A, Zanobetti M $\&$ Pini R. Prognostic scores for early stratification of septic patients admitted to an emergency department-high dependency unit. European Journal of Emergency Medicine 201421 254-259. (https://doi. org/10.1097/MEJ.0000000000000075)

9 Singer M, Deutschman CS, Seymour CW, Shankar-Hari M, Annane D, Bauer M, Bellomo R, Bernard GR, Chiche JD, Coopersmith CM, et al. The Third International Consensus definitions for sepsis and septic shock (Sepsis-3). JAMA 2016315 801-810. (https://doi.org/10.1001/ jama.2016.0287)

10 Kruger S, Ewig S, Giersdorf S, Hartmann O, Suttorp N, Welte T \& German Competence Network for the Study of Community Acquired Pneumonia. Cardiovascular and inflammatory biomarkers to predict short- and long-term survival in community-acquired pneumonia: results from the German Competence Network, CAPNETZ. American Journal of Respiratory and Critical Care Medicine 2010182 1426-1434. (https://doi.org/10.1164/rccm.201003-0415OC)

11 Tigabu BM, Davari M, Kebriaeezadeh A \& Mojtahedzadeh M. Fluid volume, fluid balance and patient outcome in severe sepsis and septic 
shock: a systematic review. Journal of Critical Care 201848 153-159. (https://doi.org/10.1016/j.jcrc.2018.08.018)

12 Sakr Y, Rubatto Birri PN, Kotfis K, Nanchal R, Shah B, Kluge S, Schroeder ME, Marshall JC, Vincent JL \& Intensive Care Over Nations Investigators. IHigher fluid balance increases the risk of death from sepsis: results from a Large International Audit. Critical Care Medicine 201745 386-394. (https://doi.org/10.1097/CCM.0000000000002189)

13 Struck J, Morgenthaler NG \& Bergmann A. Copeptin, a stable peptide derived from the vasopressin precursor, is elevated in serum of sepsis patients. Peptides 200526 2500-2504. (https://doi.org/10.1016/j. peptides.2005.04.019)

14 Morgenthaler NG, Muller B, Struck J, Bergmann A, Redl H \& ChristCrain M. Copeptin, a stable peptide of the arginine vasopressin precursor, is elevated in hemorrhagic and septic shock. Shock $2007 \mathbf{2 8}$ 219-226. (https://doi.org/10.1097/SHK.0b013e318033e5da)

15 Palmiere C \& Augsburger M. Copeptin as a diagnostic biomarker for sepsis-related deaths. Peptides 201459 75-78. (https://doi. org/10.1016/j.peptides.2014.07.011)

16 Jochberger S, Dorler J, Luckner G, Mayr VD, Wenzel V, Ulmer H, Morgenthaler NG, Hasibeder WR \& Dunser MW. The vasopressin and copeptin response to infection, severe sepsis, and septic shock. Critical Care Medicine 200937 476-482. (https://doi.org/10.1097/ CCM.0b013e3181957532)

17 Lesur O, Roussy JF, Chagnon F, Gallo-Payet N, Dumaine R, Sarret P, Chraibi A, Chouinard L \& Hogue B. Proven infection-related sepsis induces a differential stress response early after ICU admission. Critical Care 201014 R131. (https://doi.org/10.1186/cc9102)

18 Morgenthaler NG, Struck J, Jochberger S \& Dunser MW. Copeptin: clinical use of a new biomarker. Trends in Endocrinology and Metabolism 200819 43-49. (https://doi.org/10.1016/j. tem.2007.11.001)

19 Schuetz P \& Muller B. The hypothalamic-pituitary-adrenal axis in critical illness. Endocrinology and Metabolism Clinics of North America 200635 823-38, x. (https://doi.org/10.1016/j.ecl.2006.09.013)

20 Nickel CH, Bingisser R \& Morgenthaler NG. The role of copeptin as a diagnostic and prognostic biomarker for risk stratification in the emergency department. BMC Medicine 201210 7. (https://doi. org/10.1186/1741-7015-10-7)

21 Schuetz P, Wolbers M, Christ-Crain M, Thomann R, Falconnier C, Widmer I, Neidert S, Fricker T, Blum C, Schild U, et al. Prohormones for prediction of adverse medical outcome in community-acquired pneumonia and lower respiratory tract infections. Critical Care 2010 14 R106. (https://doi.org/10.1186/cc9055)

22 De Marchis GM, Katan M, Weck A, Fluri F, Foerch C, Findling O, Schuetz P, Buhl D, El-Koussy M, Gensicke H, et al. Copeptin adds prognostic information after ischemic stroke: results from the CoRisk study. Neurology 201380 1278-1286. (https://doi.org/10.1212/ WNL.0b013e3182887944)

23 Ostadal P, Kruger A, Zdrahalova V, Janotka M, Vondrakova D, Neuzil P $\&$ Prucha M. Blood levels of copeptin on admission predict outcomes in out-of-hospital cardiac arrest survivors treated with therapeutic hypothermia. Critical Care 201216 R187. (https://doi.org/10.1186/ cc11671)

24 Potocki M, Breidthardt T, Mueller A, Reichlin T, Socrates T, Arenja N, Reiter M, Morgenthaler NG, Bergmann A, Noveanu M, et al. Copeptin and risk stratification in patients with acute dyspnea. Critical Care 201014 R213. (https://doi.org/10.1186/cc9336)

25 Katan M \& Christ-Crain M. The stress hormone copeptin: a new prognostic biomarker in acute illness. Swiss Medical Weekly 2010140 w13101. (https://doi.org/10.4414/smw.2010.13101)

26 Stolz D, Christ-Crain M, Morgenthaler NG, Leuppi J, Miedinger D, Bingisser R, Muller C, Struck J, Muller B \& Tamm M. Copeptin, $\mathrm{C}$-reactive protein, and procalcitonin as prognostic biomarkers in acute exacerbation of COPD. Chest 2007131 1058-1067. (https://doi. org/10.1378/chest.06-2336)
27 Muller B, Morgenthaler N, Stolz D, Schuetz P, Muller C, Bingisser R, Bergmann A, Tamm M \& Christ-Crain M. Circulating levels of copeptin, a novel biomarker, in lower respiratory tract infections. European Journal of Clinical Investigation 200737 145-152. (https://doi. $\operatorname{org} / 10.1111 / \mathrm{j} .1365-2362.2007 .01762 . x)$

28 Katan M, Morgenthaler N, Widmer I, Puder JJ, Konig C, Muller B \& Christ-Crain M. Copeptin, a stable peptide derived from the vasopressin precursor, correlates with the individual stress level. Neuro Endocrinology Letters 200829 341-346.

29 Schuetz P, Hausfater P, Amin D, Haubitz S, Fassler L, Grolimund E, Kutz A, Schild U, Caldara Z, Regez K, et al. Optimizing triage and hospitalization in adult general medical emergency patients: the triage project. BMC Emergency Medicine 201313 12. (https://doi. org/10.1186/1471-227X-13-12)

30 Raith EP, Udy AA, Bailey M, McGloughlin S, MacIsaac C, Bellomo R, Pilcher DV \& Australian and New Zealand Intensive Care Society (ANZICS) Centre for Outcomes and Resource Evaluation (CORE). Prognostic accuracy of the SOFA score, SIRS criteria, and qSOFA score for in-hospital mortality among adults with suspected infection admitted to the intensive care unit. JAMA 2017317 290-300. (https:// doi.org/10.1001/jama.2016.20328)

31 Pandharipande PP, Shintani AK, Hagerman HE, St Jacques PJ, Rice TW, Sanders NW, Ware LB, Bernard GR \& Ely EW. Derivation and validation of $\mathrm{SpO}_{2} / \mathrm{FiO}_{2}$ ratio to impute for $\mathrm{PaO}_{2} / \mathrm{FiO}_{2}$ ratio in the respiratory component of the sequential organ failure assessment score. Critical Care Medicine 200937 1317-1321. (https://doi. org/10.1097/CCM.0b013e31819cefa9)

32 Morgenthaler NG, Struck J, Alonso C \& Bergmann A. Assay for the measurement of copeptin, a stable peptide derived from the precursor of vasopressin. Clinical Chemistry 200652 112-119. (https://doi. org/10.1373/clinchem.2005.060038)

33 Haag E, Gregoriano C, Molitor A, Kloter M, Kutz A, Mueller B \& Schuetz P. Does mid-regional pro-adrenomedullin (MR-proADM) improve the sequential organ failure assessment-score (SOFA score) for mortality-prediction in patients with acute infections? Results of a prospective observational study. Clinical Chemistry and Laboratory Medicine 202159 1165-1176. (https://doi.org/10.1515/cclm-20201566)

34 Christ-Crain M, Morgenthaler NG \& Fenske W. Copeptin as a biomarker and a diagnostic tool in the evaluation of patients with polyuria-polydipsia and hyponatremia. Best Practice and Research: Clinical Endocrinology and Metabolism 201630 235-247. (https://doi. org/10.1016/j.beem.2016.02.003)

35 Michell RH, Kirk CJ \& Billah MM. Hormonal stimulation of phosphatidylinositol breakdown with particular reference to the hepatic effects of vasopressin. Biochemical Society Transactions 19797 861-865. (https://doi.org/10.1042/bst0070861)

36 Penit J, Faure M \& Jard S. Vasopressin and angiotensin II receptors in rat aortic smooth muscle cells in culture. American Journal of Physiology 1983244 E72-E82. (https://doi.org/10.1152/ ajpendo.1983.244.1.E72)

37 Thibonnier M. Use of vasopressin antagonists in human diseases. Kidney International: Supplement 198826 S48-S51.

38 Barat C, Simpson L \& Breslow E. Properties of human vasopressin precursor constructs: inefficient monomer folding in the absence of copeptin as a potential contributor to diabetes insipidus. Biochemistry 200443 8191-8203. (https://doi.org/10.1021/ bi0400094)

39 Gomes DA, de Almeida Beltrao RL, de Oliveira Junior FM, da Silva Junior JC, de Arruda EPC, Lira EC \& da Rocha MJA. Vasopressin and copeptin release during sepsis and septic shock. Peptides 2021136 170437. (https://doi.org/10.1016/j.peptides.2020.170437)

40 Saeed K, Wilson DC, Bloos F, Schuetz P, van der Does Y, Melander O, Hausfater P, Legramante JM, Claessens YE, Amin D, et al. The early identification of disease progression in patients with suspected https://ec.bioscientifica.com https://doi.org/10.1530/EC-21-0211 (c) 2021 The authors Published by Bioscientifica Ltd

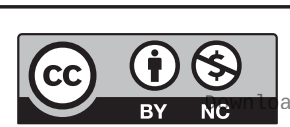

This work is licensed under a Creative Commons Attribution-NonCommercial 4.0 International License. ded from Bioscientifica.com at 04/26/2023 01:01:55PM 
infection presenting to the emergency department: a multi-centre derivation and validation study. Critical Care 201923 40. (https://doi. org/10.1186/s13054-019-2329-5)

41 Angeletti S, Spoto S, Fogolari M, Cortigiani M, Fioravanti M, De Florio L, Curcio B, Cavalieri D, Costantino S \& Dicuonzo G. Diagnostic and prognostic role of procalcitonin (PCT) and MR-pro-adrenomedullin (MR-proADM) in bacterial infections. APMIS 2015123 740-748. (https://doi.org/10.1111/ apm.12406)

42 Wang H, Kang X, Shi Y, Bai ZH, Lv JH, Sun JL \& Pei HH. SOFA score is superior to Apache-II score in predicting the prognosis of critically ill patients with acute kidney injury undergoing continuous renal replacement therapy. Renal Failure 202042 638-645. (https://doi. org/10.1080/0886022X.2020.1788581)
43 Acheampong A \& Vincent JL. A positive fluid balance is an independent prognostic factor in patients with sepsis. Critical Care 201519 251. (https://doi.org/10.1186/s13054-015-0970-1)

44 Treschan TA \& Peters J. The vasopressin system: physiology and clinical strategies. Anesthesiology 2006105 599-612; quiz 39-40. (https://doi.org/10.1097/00000542-200609000-00026)

45 Annborn M, Dankiewicz J, Nielsen N, Rundgren M, Smith JG, Hertel S, Struck J \& Friberg H. CT-proAVP (copeptin), MR-proANP and peroxiredoxin 4 after cardiac arrest: release profiles and correlation to outcome. Acta Anaesthesiologica Scandinavica 201458 428-436. (https://doi.org/10.1111/aas.12282)

46 Mockel M \& Searle J. The positive predictive value of ct-proAVP (copeptin) in patients with STEMI. Heart 201399 1475. (https://doi. org/10.1136/heartjnl-2013-304217)

Received in final form 22 July 2021

Accepted 28 July 2021

Accepted Manuscript published online 28 July 2021
This work is licensed under a Creative Commons Attribution-NonCommercial 4.0 International License. ded from Bioscientifica.com at 04/26/2023 01:01:55PM via free access 